IJBPAS, December, Special Issue, 2021, 10(12): 159-170

ISSN: 2277-4998

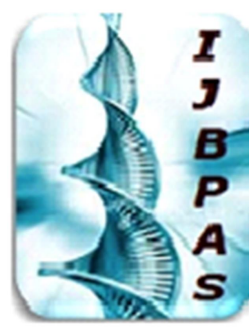

International Journal of Biology, Pharmacy and Allied Sciences (IJBPAS)

'A Bridge Betueen Caboratory med QRendo'

Www.ibpas.com

\title{
FORMULATION AND EVALUATION OF KETOCONAZOLE EMULGEL FOR TOPICAL DRUG DELIVERY
}

\section{PRIYA SHARMA*, SEEMA SAINI AND NARESH SINGH GILL}

Rayat Institute of Pharmacy, Railmajra, Punjab, India

*Corresponding Author: E Mail: Priya Sharma: priya199404.pps@gmail.com

Received $9^{\text {th }}$ May 2021; Revised $10^{\text {th }}$ July 2021; Accepted $29^{\text {th }}$ Aug. 2021; Available online $15^{\text {th }}$ Dec. 2021

https://doi.org/10.31032/IJBPAS/2021/10.12.1013

\begin{abstract}
The main aim of the present research work was to investigate the potential of emulgel in enhancing the topical delivery of Ketoconazole. To formulate Ketoconazole emulgel, two gelling agents were used: Carbopol-934 and Carbopol-940. The emulgel which were prepared are evaluated for their physical appearance, $\mathrm{pH}$ measurement, spreadability, viscosity, drug release, antifungal test, skin irritation test, and stability. Comparison was done by using commercially available Ketoconazole cream. The prepared formulation of emulgel showed acceptable physical properties including color, homogeneity, consistency, $\mathrm{pH}$ value and spreadability. It was found that the antifungal property and drug release for optimized formulation is higher than the marketed Ketoconazole cream. The highest activity was observed with F2 formulation, where percentage inhibition found to be $71.53 \%$ than the marketed product, which was found $45.43 \%$. The cumulative amount of drug release range varied between $76.69 \%$ to $66.13 \%$. at $24 \mathrm{hrs}$. As all the evaluation parameters were performed, so there was no skin irritation seen. It was also observed that, after storage of formulation for 3 months, stability study showed that the physical appearance, rheological study, in vitro drug release, and antifungal activity of emulgel remains unchanged. In general conclusion, it was suggested that the prepared formulation (emulgel) of drug release for sustained drug delivery in a controlled manner is succeed in comparison with cream.
\end{abstract}

Keywords: Emulgel, Ketoconazole, Topical drug delivery, antifungal activity 


\section{INTRODUCTION}

Topical delivery can be defined as the application of a drug containing formulation to the skin to directly treat cutaneous disorders (e.g. acne, psoriasis) with the intent of containing the pharmacological or other effects of drug to the surface of the skin or within. Topical drug administration through various routes applied a wide spectrum of preparation for both cosmetic and dermatological, to their health and diseased skin [3]. Topical preparations are applied to the surface of a part of the body and have effects only in a specific area of a body and are formulated in such a manner that the systemic absorption of the medicament is minimal. The most common examples of topical dosage forms are solutions, suspensions, emulsions, semisolids (e.g. powders and aerosols) among them ointments, creams, and lotions have numerous disadvantages [5].

They are usually very sticky and cause uneasiness to the patient when applied moreover they also have less spreading coefficient and need to apply with rubbing. They also exhibit the problem of stability. Due to all these factors, a major group of semisolid preparation, transparent gel has expanded its use in both cosmetics and in pharmaceutical preparation. Inspite of many advantages of gels a major limitation

\section{MATERIALS AND METHODS}

an emulsion based approach is being used so that a hydrophobic therapeutic moiety can be successfully incorporated and delivery through gels [7]. When gels and emulsions are used in combined form the dosage forms are referred as emulgels.

Emulgel are emulsions, either of the oil-inwater or water-in-oil type, which are gelled by mixing with a gelling agent. Emulsified gel is stable one and better vehicle for hydrophobic or poorly water soluble drugs. On the other hand, topical delivery system increases the contact time and mean resident time of drug at the applied site leading to an increase in local drug concentration while the pharmacological activity of Emulgel formulations may not change as rapidly as the solution form. Several antifungal agents are available in the in different topical preparations (for e.g. ointments, creams, powders for local dermatological therapy). One of these antifungal agents is Ketoconazole, which has both antifungal and antibacterial properties.

Emulgel Preparation:-Emulgel can be prepared by these three steps, which are as: STEP1: Preparation of gel using gelling agent and water by constant stirring followed by $\mathrm{pH}$ adjustment.

STEP2: Preparation of emulsion.

STEP3: Incorporation of emulsion into gel base with continuous stirring. 
Table 1: Material and Source

\begin{tabular}{|c|c|c|}
\hline S. No. & Name of the Chemical & Manufacturer/Source \\
\hline 1. & Ketoconazole & Gift sample byCadilaP'ceuticals Ltd. \\
\hline 2. & Carbopol-934 & Loba Chemicals \\
\hline 3. & Carbopol-940 & S.D. Fine chemicals Ltd. \\
\hline 4. & Light liquid paraffin & S.D. Fine chemicals Ltd. \\
\hline 5. & Span 20 & S.D. Fine chemicals Ltd. \\
\hline 6. & Tween 20 & S.D. Fine chemicals Ltd. \\
\hline 7. & Propylene glycol & S.D. Fine chemicals Ltd. \\
\hline 8. & Oleic acid & S.D. Fine chemicals Ltd. \\
\hline 9. & Acetone & S.D. Fine chemicals Ltd. \\
\hline 10. & Methanol & S.D. Fine chemicals Ltd. \\
\hline 11. & Propyl paraben & S.D. Fine chemicals Ltd. \\
\hline 12. & Potassium hydroxide & S.D. Fine chemicals Ltd. \\
\hline 13. & Sodium dihydrogen phosphate & S.D. Fine chemicals Ltd. \\
\hline 14. & Disodium hydrogen phosphate & S.D. Fine chemicals Ltd. \\
\hline 15. & Triethanolamine & S.D. Fine chemicals Ltd. \\
\hline 16. & Mentha oil & \\
\hline
\end{tabular}

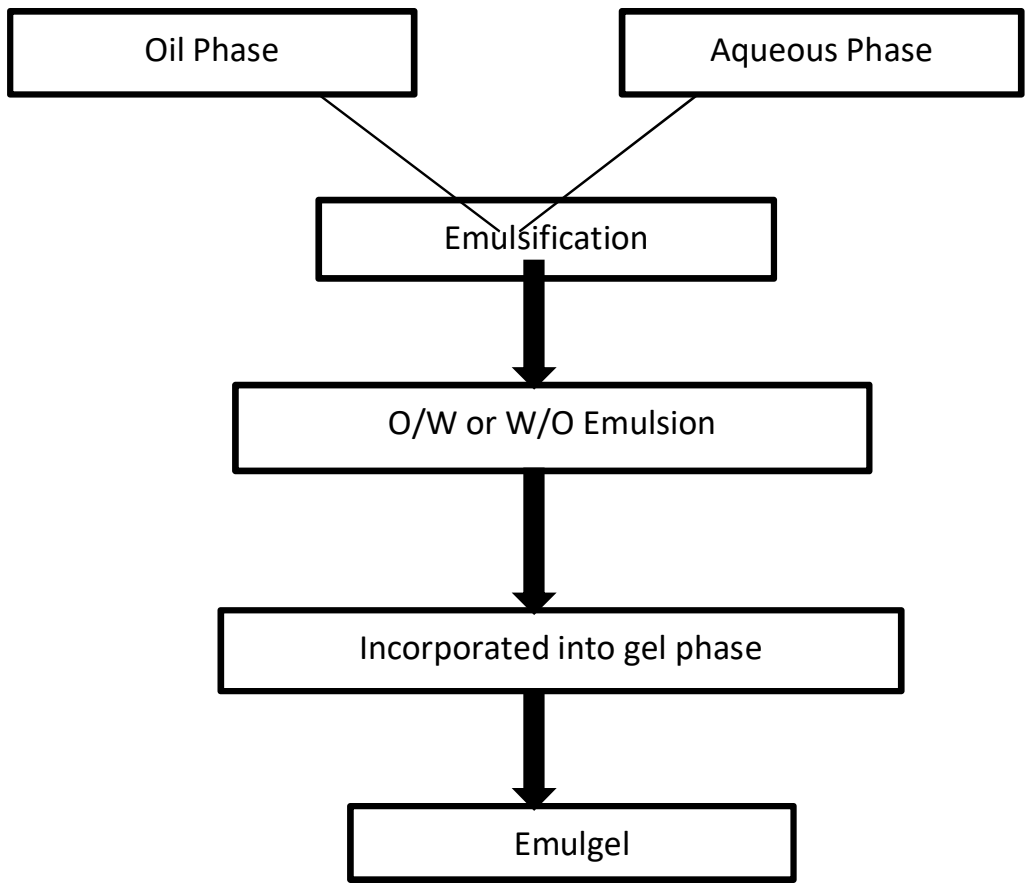

\section{Formulation of emulsion either o/w or}

w/o: The emulsion is prepared by slowly mixing oil phase and aqueous phase of the emulsion containing an emulsifying agent like spans and tweens. Before mixing the two phases, both the oily and aqueous phase are separately heated to $70-80^{\circ} \mathrm{C}$; then the oily phase can be added to the aqueous phase with continuous stirring for
15 to 20 minutes and cooled to room temperature. Preservative may also be added to the emulsion in any phase depending on its solubility

2 Formulation of gel base: The gel in formulation are prepared by dispersing a suitable polymer in purified water with constant stirring at a moderate speed to allow complete hydration and swelling of 
polymers. Then $\mathrm{pH}$ is adjusted to 6 to 6.5 using Triethanolamine (TEA). the gel in 1:1 ratio with gentle stirring to obtain the emulgel.

\section{Incorporation of emulsion into gel}

base: The obtained emulsion is mixed with

\begin{tabular}{|c|c|c|c|c|c|c|c|c|}
\hline \multirow{3}{*}{ Ingredients \%(w/w) } & & \multirow[b]{3}{*}{ F2 } & \multirow{3}{*}{$\begin{array}{c}\text { Formulation } \\
\text { F3 } \\
\end{array}$} & \multirow{2}{*}{\multicolumn{5}{|c|}{ Batches }} \\
\hline & & & & & & & & \\
\hline & F1 & & & F4 & F5 & F6 & F7 & F8 \\
\hline Ketoconazole & 1 & 1 & 1 & 1 & 1 & 1 & 1 & 1 \\
\hline Carbopol-940 & 0.5 & 1 & 1.5 & 2.0 & & & & \\
\hline Carbopol-934 & & & & & 0.5 & 1 & 1.5 & 2.0 \\
\hline Tween 20 & 0.5 & 0.5 & 0.5 & 0.5 & 0.5 & 0.5 & 0.5 & 0.5 \\
\hline Span 20 & 1 & 1 & 1 & 1 & 1 & 1 & 1 & 1 \\
\hline LiquidParaffin & 7.5 & 7.5 & 7.5 & 7.5 & 7.5 & 7.5 & 7.5 & 7.5 \\
\hline PropyleneGlycol & 5 & 5 & 5 & 5 & 5 & 5 & 5 & 5 \\
\hline Mentha Oil & 1 & 1 & 1 & 1 & 1 & 1 & 1 & 1 \\
\hline Propyl Paraben & 0.5 & 0.5 & 0.5 & 0.5 & 0.5 & 0.5 & 0.5 & 0.5 \\
\hline Methyl Paraben & 0.5 & 0.5 & 0.5 & 0.5 & 0.5 & 0.5 & 0.5 & 0.5 \\
\hline Water & q.s & q.S & q.s & q.s & q.s & q.s & q.s & q.s \\
\hline
\end{tabular}

\section{EVALUATION}

a) Physical Examination: The prepared emulgel formulation were inspected visually for their colour, homogeneity, consistency, grittiness and phase separation.

b) $\mathbf{p H}$ Measurement: The $\mathrm{pH}$ of emulgel formulation was determined by using digital $\mathrm{pH}$ meter. One gram of gel was dissolved in $100 \mathrm{ml}$ of distilled water and kept for two hours. The measurement of $\mathrm{pH}$ of each formulation was done in triplicate and average values were calculated.

c) Spreadability: Spreadability was determined by apparatus suggested by Mutimer et al (1956) which was suitably modified in the laboratory and used for the study. About $2 \mathrm{gm}$ emulgel under study was placed on this ground slide. The emulgel was then sandwiched between this slide and another glass slide having the dimension of fixed ground slide and provided with the hook. Weight of one $g$ was placed on the top of the two slides for 5 minutes to expel air and to provide a uniform film of the emulgel between the slides. Measured quantity of weight was placed in the pan attached to the pulley with the help of hook. The time (in sec) required by the top slide to separate from ground slide was noted. A shorter interval indicates better spreadability.

It is calculated by using the formula $=$ M.L/T

Where, $\mathrm{S}=$ spreadability, $\mathrm{M}=$ Weight tied to upper slide, $\mathrm{L}=$ Length of glass slides, $\mathrm{T}=$ Time taken to separate the slides completely from each other

d) Drug Content Determination: Accurately weighed 1 gm of emulgel was dissolved in $100 \mathrm{ml}$ of methanolic phosphate buffer $\mathrm{pH} 5.5$ in volumetric flask. It was kept for 2 hours and 
shaken well to mix it properly. The solution was passed through the filter paper and filtered. The absorbance was measured spectrophotometrically at 242 $\mathrm{nm}$ after appropriate dilution against corresponding Buffer concentration as blanks. The drug content was determined using standard plot with the help of following formula.

Drug Content $=($ Concentration $\times$ Dilution Factor $\mathrm{x}$ Volume taken) $\mathrm{x}$ Conversion Factor

e) In Vitro Release Study: The in vitro drug release studies of the emulgel were carried out in modified Diffusion Cell using Dialysis membrane (Himedia laboratories Pvt. Ltd: dry, unwashed, open ended; flat width: $28.46 \mathrm{~nm}$; inflated diameter: $17.5 \mathrm{~nm}$; Length: $1 \mathrm{~m}$ ). The membrane was soaked in Phosphate buffer $\mathrm{pH} 5.5$ for $9-12 \mathrm{~h}$ and clamped carefully to one end of the hollow glass tube of dialysis cell $(2.3 \mathrm{~cm}$ diameter; $4-16 \mathrm{~cm}^{2}$ area). Then emulgel was spread uniformly on the dialysis membrane. Fifty $\mathrm{ml}$ of phosphate buffer was taken in a beaker, which was used as receptor compartment. The donor compartment was kept in contact with receptor compartment. This whole assembly was kept on a magnetic stirrer and solution on the receptor side was stirred continuously using a magnetic bead and temperature of the cell was maintained at $37^{\circ} \mathrm{C}$. Sample of $5 \mathrm{ml}$ was withdrawn at suitable time interval and replaced with equal amounts of fresh dissolution media. Samples were analyzed spectrophotometrically at $242 \mathrm{~nm}$ and cumulative $\%$ drug release was calculated. The difference between the readings of drug release and control was used as the actual reading in each case.

f) Stability Study: Stability study was performed on F2 formulations. The preparations were packed in collapsible aluminium tubes $(5 \mathrm{~g})$ and subjected to stability study at $25^{\circ} \mathrm{C}$ for a period of 2 months. Samples were withdrawn at interval of 15 days and were evaluated for physical appearance, rheological properties and drug content.

Table 3: Absorbance of Ketoconazole at different concentration

\begin{tabular}{|c|c|}
\hline Concentration $(\mu \mathrm{g} / \mathrm{ml})$ & Absorbance \\
\hline 25 & 0.161 \\
\hline 50 & 0.206 \\
\hline 100 & 0.321 \\
\hline 150 & 0.436 \\
\hline 200 & 0.557 \\
\hline 250 & 0.661 \\
\hline 300 & 0.775 \\
\hline
\end{tabular}




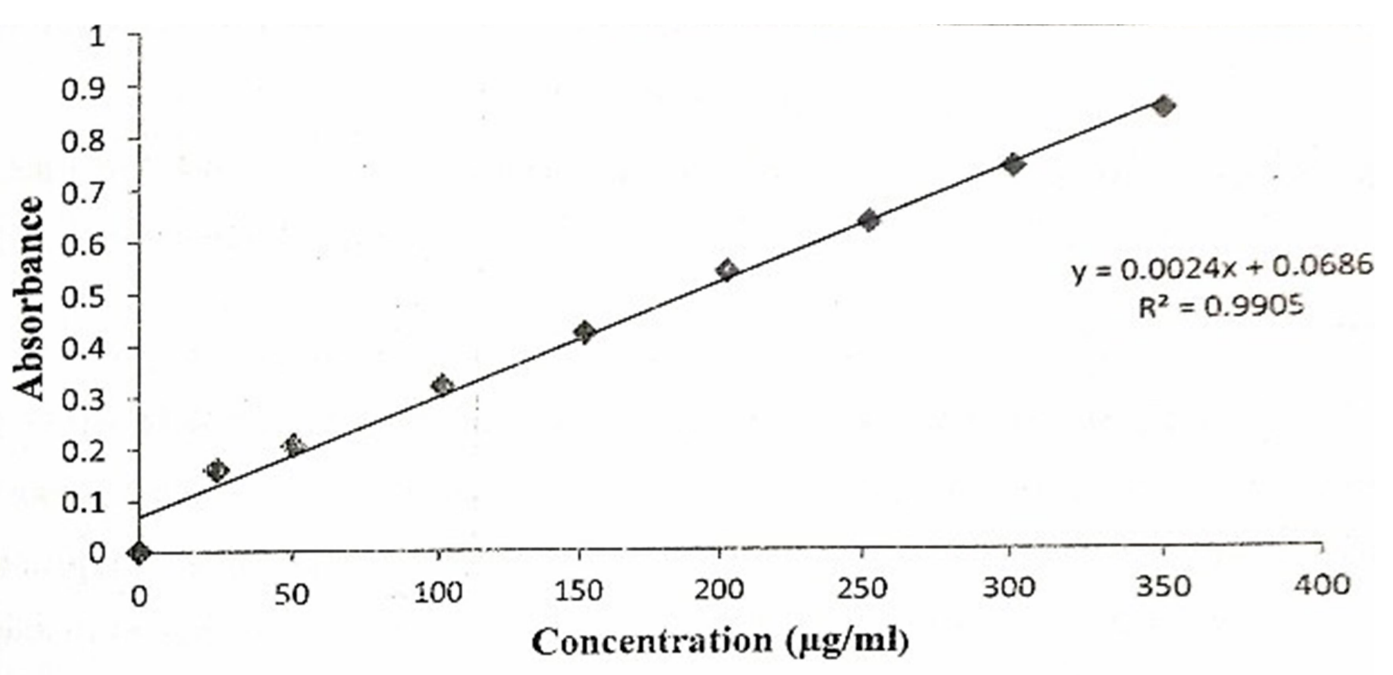

Figure 1: Standard Curve of Ketoconazole
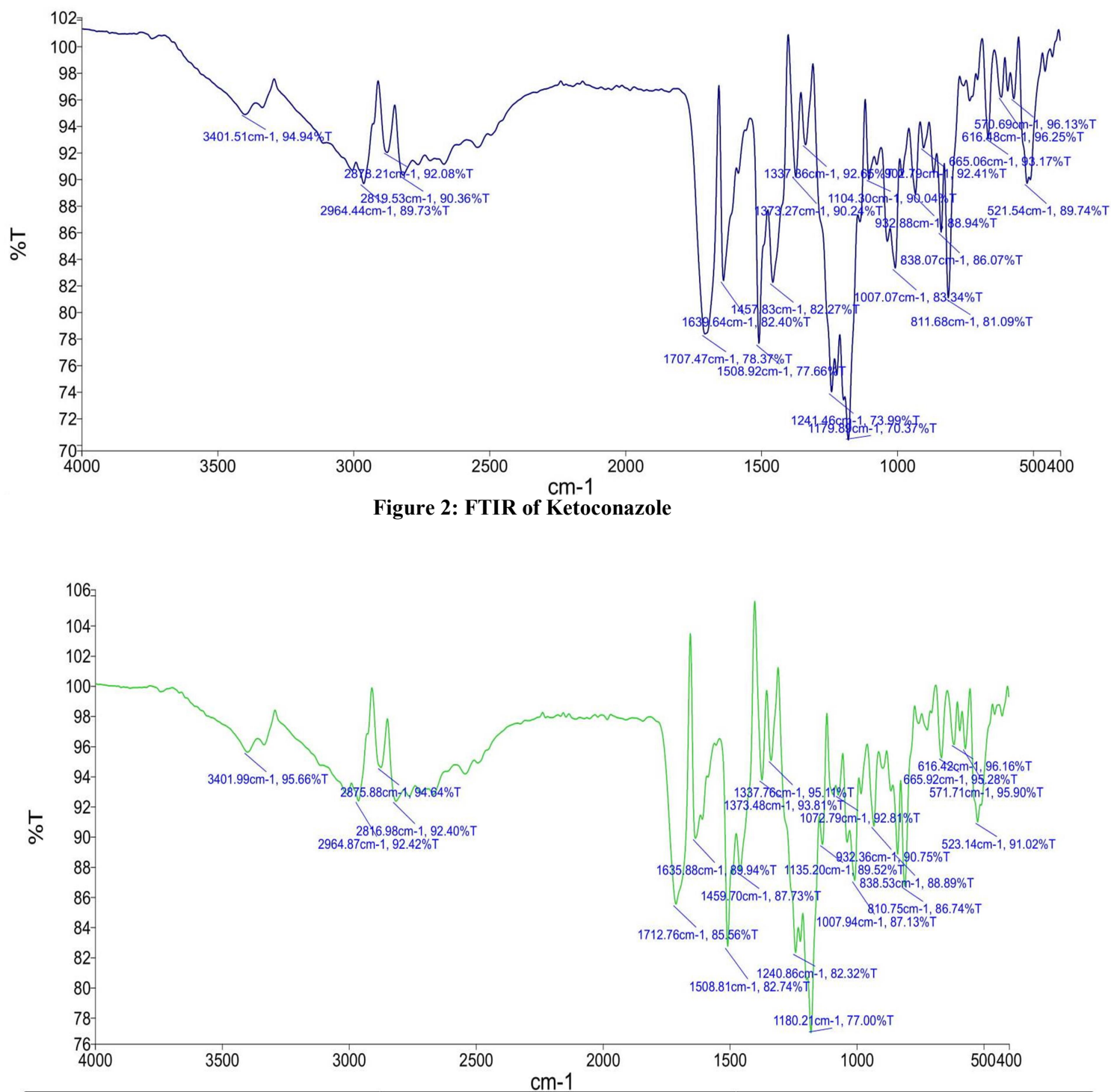

Figure 3: FTIR of Ketoconazole and Carbopol-934 


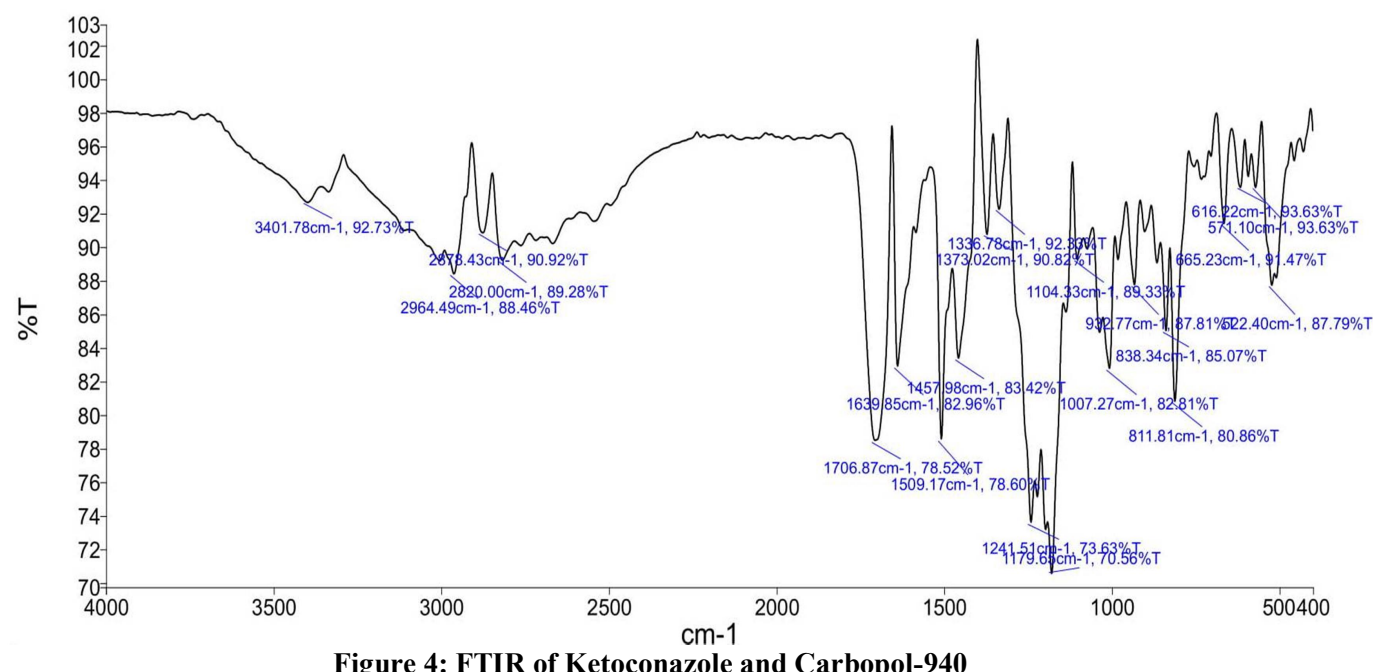

\section{RESULTS AND DISCUSSION}

The various formulations of ketoconazole were prepared by using different polymers i.e. Carbopol-934 and Carbopol-940 as gelling agent. Prepared formulation of Ketoconazole were evaluated for the physiochemical parameters such as physical examination, $\mathrm{pH}$ measurement, spreadability, drug content, in vitro drug release, stability study.

a) Physical Examination: The prepared formulation showed white colour, bitter in taste. No phase separation was noticed, it shows good homogeneity and consistency. It is freely soluble in methanol, slightly soluble in ethanol and insoluble in water. The melting range was found to be 144$146^{\circ} \mathrm{C}$ (Table 4).

b) $\mathbf{p H}$ Measurement: It was in the range of $5.4-6.2$ which was similar to $\mathrm{pH}$ of the skin Graph 1. c) Spreadability: It was found that, it decreases with increase in viscosity, i.e. why spreadability and viscosity are inversely proportional. From results, it was concluded that formulation F2 showed desired spreadability with $1 \%$ Carbopol-940 Graph 2.

d) Drug Content: The drug content was determined for all the formulations by UV spectrophotometer method. The result varied from $82.2 \%$ and $91.3 \%$ as shown in Graph 3 below. It indicated that drug dispensed uniformly throughout the Emulgel. Formulation F2 showed maximum drug content.

e) In Vitro Drug Release Study: The cumulative amount of drug release range varied between $76.69 \%$ to $66.13 \%$ in 12 hours respectively. This study showed that, as the concentration of polymer increases the amount of drug release decreases. So, the result 
proves that formulation F2 showed

$71.53 \%$ drug release data with $1 \%$

Carbopol-940 (Table 5, Graph 4).

f) Stability Study: Test result of study is shown in graph below. Stability study of formulation $\mathrm{F} 2$ was performed at $25^{\circ} \mathrm{C}$ with
1\% Carbopol-940 for a period of 2 months. Hence, it is proved that the physical stability of the emulgel remains unchanged after storage upto 2 months at specified condition (Graph 5).

Table 4: Physiochemical characteristics of Ketoconazole Emulgel

\begin{tabular}{|c|c|c|c|c|c|c|}
\hline S. No. & $\begin{array}{c}\text { Formulation } \\
\text { Code }\end{array}$ & Colour & $\begin{array}{c}\text { Phase } \\
\text { separation }\end{array}$ & Grittiness & Homogeneity & Consistency \\
\hline $\mathbf{1}$ & F1 & White & None & - & Excellent & +++ \\
\hline 2 & F2 & White & None & - & Excellent & +++ \\
\hline 3 & F3 & White & None & - & Excellent & +++ \\
\hline $\mathbf{5}$ & F4 & White & None & - & Excellent & +++ \\
\hline $\mathbf{6}$ & F5 & White & None & - & Excellent & ++ \\
\hline 7 & F6 & White & None & - & Excellent & + \\
\hline $\mathbf{8}$ & F7 & White & None & - & Fair & ++ \\
\hline
\end{tabular}

Excellent+++, Good++, Satisfactory+

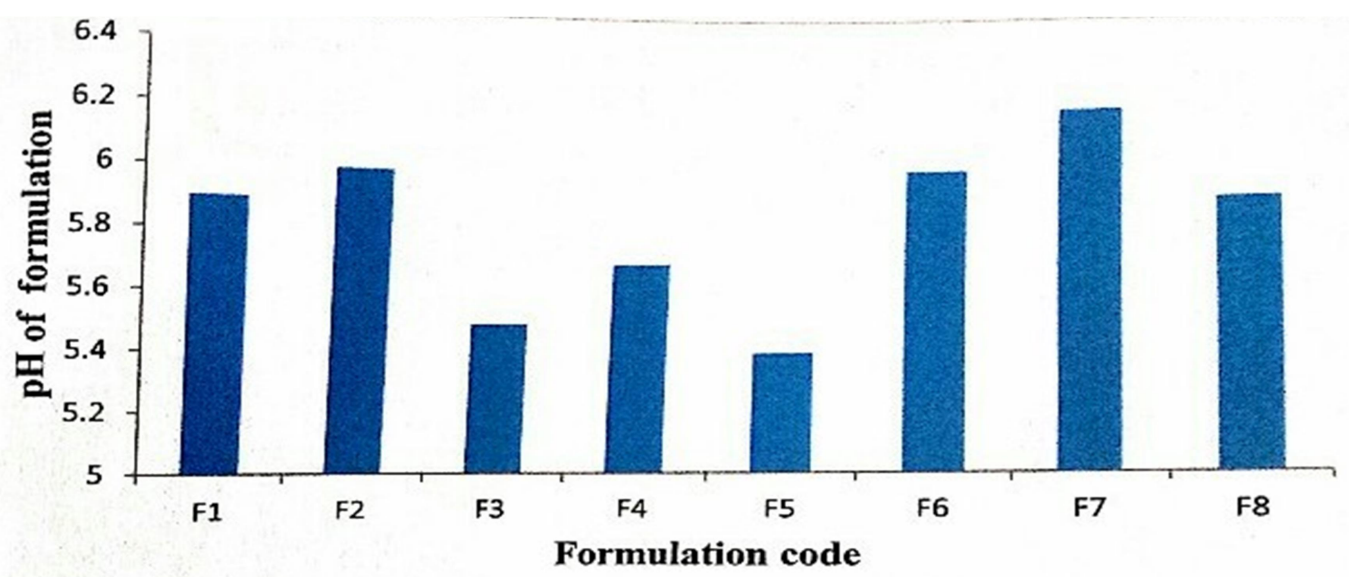

Graph 1: pH of Different Emulgel Formulations F1 - F8

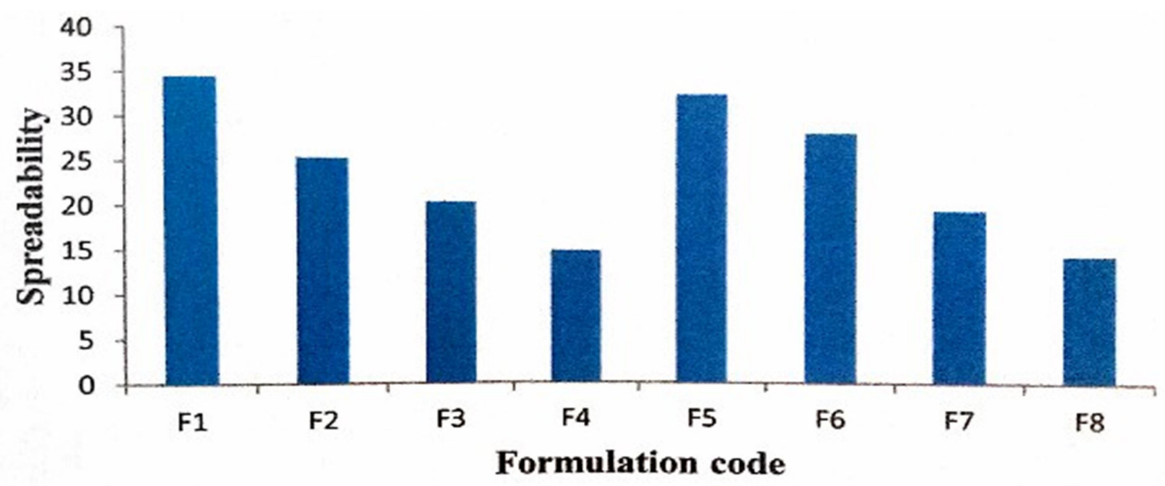

Graph 2: Spreadability of Diferrent Formulations 


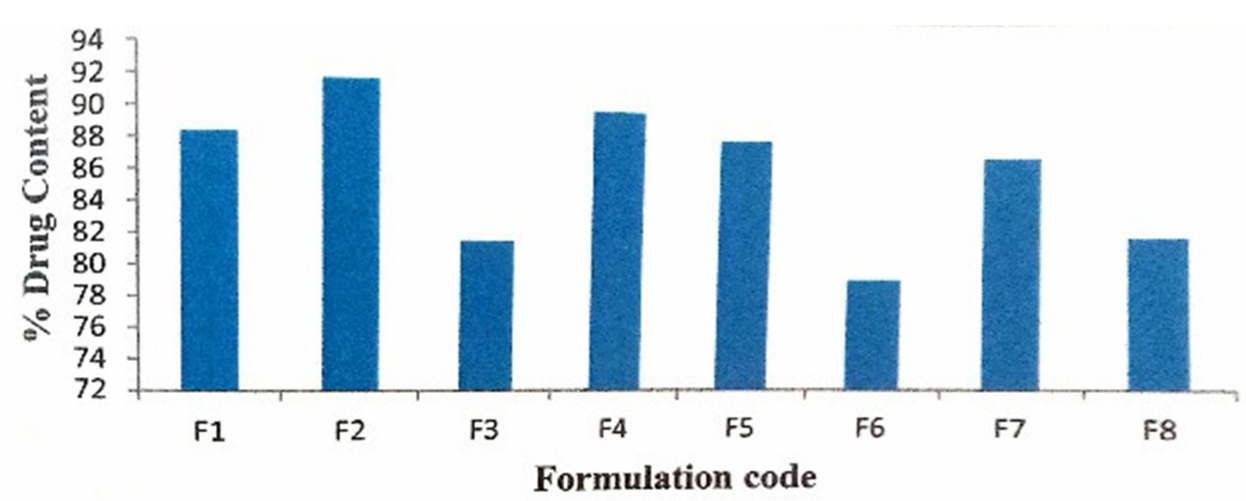

Graph 3: Drug Content of Formulations

Table 5: In Vitro drug release study of Ketoconazole emulgel formulations

\begin{tabular}{|c|c|c|c|c|c|c|c|c|}
\hline Time (hours) & F1 & F2 & F3 & F4 & F5 & F6 & F7 & F8 \\
\hline 0 & 0.00 & 0.00 & 0.00 & 0.00 & 0.00 & 0.00 & 0.00 & 0.00 \\
\hline 0.5 & 13.68 & 4.52 & 14.33 & 3.66 & 11.93 & 4.428 & 6.86 & 7.874 \\
\hline 1.0 & 18.17 & 6.882 & 19.85 & 17.11 & 15.37 & 7.59 & 9.493 & 10.36 \\
\hline 1.5 & 21.65 & 11.38 & 23.83 & 20.35 & 19.61 & 15.34 & 14.175 & 12.53 \\
\hline 2.0 & 25.22 & 13.67 & 26.83 & 21.99 & 22.21 & 18.53 & 20.21 & 14.67 \\
\hline 2.5 & 29.43 & 17.17 & 28.67 & 22.41 & 25.67 & 23.41 & 25.94 & 16.322 \\
\hline 3.0 & 34.05 & 18.81 & 30.25 & 23.40 & 27.46 & 25.67 & 28.74 & 17.23 \\
\hline 3.5 & 39.92 & 21.08 & 34.23 & 24.34 & 29.88 & 27.04 & 31.53 & 18.23 \\
\hline 4.0 & 43.25 & 28.65 & 38.08 & 25.59 & 32.76 & 27.64 & 35.10 & 20.93 \\
\hline 4.5 & 47.45 & 33.71 & 40.03 & 27.02 & 36.43 & 29.28 & 37.97 & 21.12 \\
\hline 5.0 & 51.19 & 34.55 & 42.19 & 28.66 & 39.26 & 30.54 & 41.33 & 24.19 \\
\hline
\end{tabular}
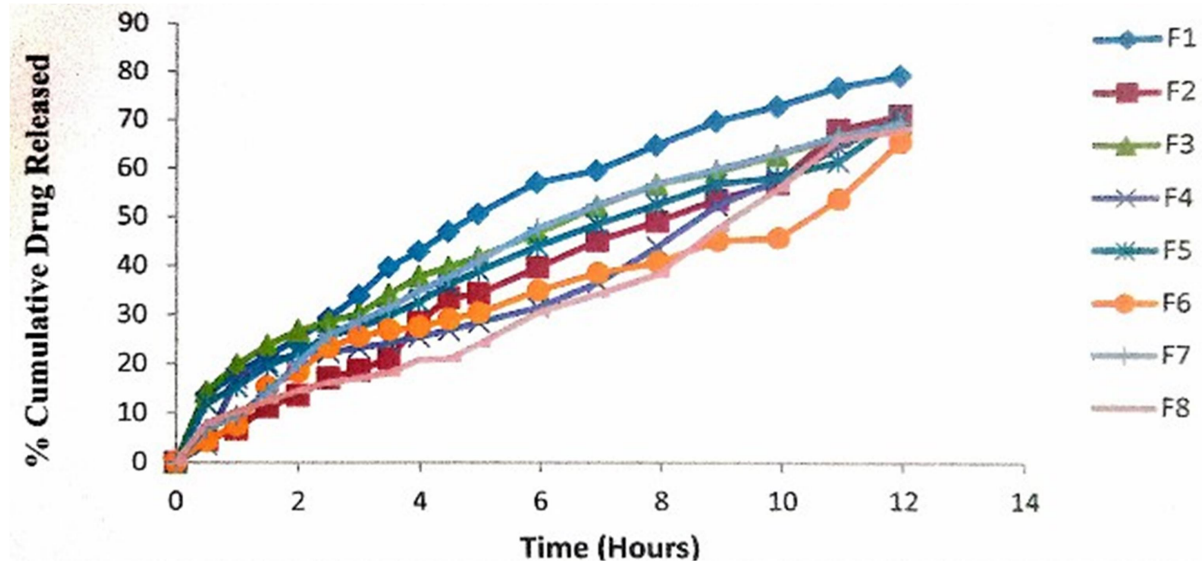

Graph 4: In Vitro Cumulative \% Drug Release profile of Formulations

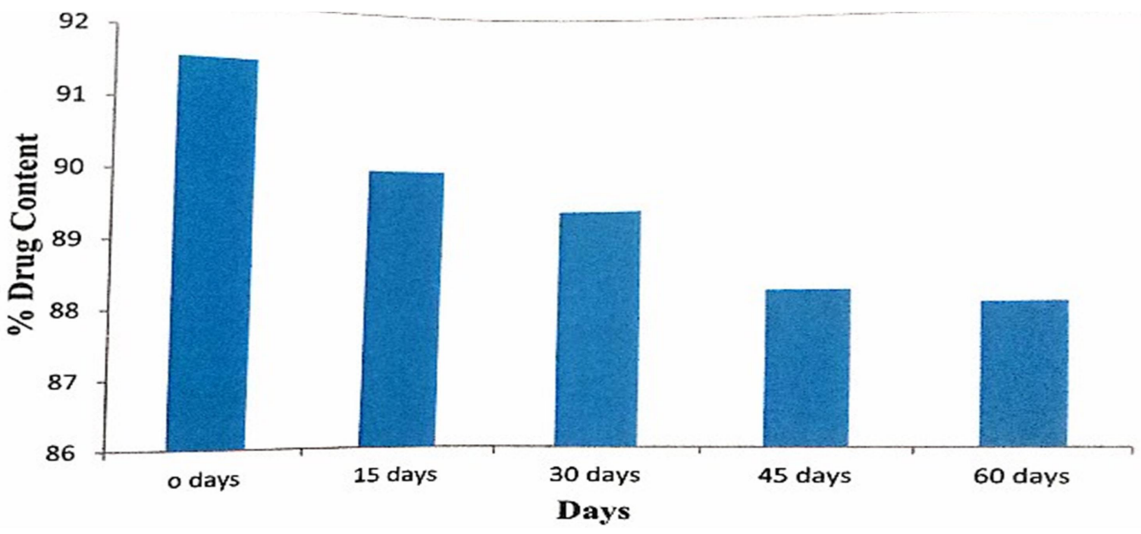

Graph 5: Stability Study data for formulation F2 


\section{CONCLUSION}

As we know, Emulgel have emerged as a promising drug delivery system for the delivery of hydrophobic drugs. They have several properties such as greaseless, easily spreadable, easily removable, emollient, non-staining, long shelf life, bio friendly, transparent and pleasing appearance. The emulgel of Ketoconazole was prepared by using Carbopol-934 and Carbopol-940 as a gelling agent. Preformulation study was also carried out to know the Organoleptic characteristics, melting point, UV absorption maxima, partition coefficient, solubility study. The stability study of formulation (F2) at $25^{\circ} \mathrm{C}$ showed no significant changes in drug content. Formulation F2 containing 1\% Carbopol940 was selected as best formulation.

\section{ACKNOWLEDGEMENT}

Author feels highly thanks to Rayat Institute of Pharmacy for providing all the necessary sources for the completion of this research work.

\section{REFERENCES}

[1] Njoku ANU, Okafor JI, Gugnani HC. Yeast-like fungi recovered from normal human skin in Nsukka (Nigeria): Antonie Van Leeuwenhoek. Journal of Microbiology and Serology 1976; 15:101-105.

[2] Gugnami HC, Okafor JI. Mycotic flora of the intestine and other internal organs of certain reptiles and amphibians with special reference to 56 characterizations of Basidiobolus isolates. Mykosen. Journal of Medical and Vaterinary Mycology 1980; 23:260-268.

[3] Teena O, Sonali N. Formulation and evaluation of mefenamic acid emulgel. International Journal of Pharmaceutical Research and Development 2014; 12:91-100.

[4] Testrake DI, Beker V, Yangco BC, Okafor JI. The effect of nutrition on morphology and pigment production of basidiobolus $\mathrm{sp}$. Presented at the $3^{\text {rd }}$ International Mycological Congress $28^{\text {th }}$ August$3^{\text {rd }}$ September at Tokyo, Japan 1983; 46:261-278.

[5] Ashara KC, Paun JS, Soniwala MW, Chavada JR, Mori NM. Micro-emulsion based Emulgel: A novel topical drug delivery system. Asian Pacific Journal of Topical Diseases 2014; 1:527-532.

[6] Yangco BG, Testrake DI, Okafor JI. Phialophorarichardisae isolated from infected Guman Bone: morphological, physiological and antifungal suspectibility studies. Mycopathologia 1984; 86:103-111.

[7] Setty CM, Babubhai SR, Pathan IB. Development of valdecoxib topical gels: Effect of formulation variables 
on the release of valdecoxib. International Journal of Pharmacy and Pharmaceutical Science 2012; 2:70-73.

[8] Erer B, Galimberti M, Lucarelli G, Giardini C, Polchi P, Baronciani D. Trichosporon beigelii. A life threatning pathogen in immunecompromised hosts in Bone Marrow Transplant. ClinInfict Dis 2000: 25:745-749.

[9] Ebright JR, Fairfax MR, Vazquez JA. Tricho sporonasahii. NonCandida yeast that caused fatal saptic shock in a patient without cancer or neutropenia. ClinInfict Dis $2001 ; 33: 28-30$.

[10] Gallis HA, Drew RH Pickard WW. Amphoteracin B: 30 year of clinical experience. Ref Infect Dis $1990 ; 12: 308-29$.

[11] Hiemenz JR, Walsh TJ. Lipid formulation of amphotericin B: Recent Progress and future directions. Clin Infect Dis 1996; 22:133-44.

[12] Wong-Beringer A, Jacobs RA, Guglielmo BJ. Lipid formulations of amphotericin B: clinical efficacy and toxicities. Cin Infect Dis 1998; 27:18-603.

[13] White MH, Anaissie EJ, Kusne S. Amphoteracin B lipid complex for invasive fungal infection: analysis of safety and efficacy in 556 cases. Clin Infect Dis 1997; 24:42-635.

[14] Walsh TJ, Hiemenz JW, Seibel NL. Amphoteracin B lipid complex for invasive fungal infection: analysis of safety and efficacy in 556 cases. Cin Infect Dis 1998; 26:1383-96.

[15] Ashara KC, Paun JS, Soniwala MW, Chavada JR, Mori NM. Micro-emulsion based Emulgel: A novel topical drug delivery system. Asian Pacific Journal of Topical Diseases 2014; 1:527-532.

[16] Setty CM, Babubhai SR, Pathan IB. Development of valdecoxib topical gels: Effect of formulation variables on the release of valdecoxib. International Journal of Pharmacy and Pharmaceutical Science 2012; 2:70-73.

[17] Thakur V, Prashar B, Arora S. Formulation and in vitro Evaluation of gel for Topical Delivery of Antifungal Agent Fluconazole using Different Penetration Enhancers. Drug Invention Today 2012; 8:414-419.

[18] Aher SD, Banerjee SK, Gadhave MV, Gaikwad DD. Emulgel: A new dosage form for topical drug delivery. International Journal of Institutional Pharmacy and life Sciences 2013; 3:1-10. 
[19] Gaur PK, Mishra S, Purohit s, Dave k. Transdermal drug delivery system: A review. Asian Journal of Pharmaceutical and Clinical Research 2009; 2:14-20.

[20] Subranayam N, Ghosal SK, Moulik SP. Enhanced in vitro percutaneous absorption and in vivo anti-inflammatory effect of a selective. Cyclooxygenase inhibitor using microemulsion. Drug DevInd Pharm 2005; 54:250-270.

[21] Bhatt P, Gnanaranjan G. Emulgel: A novel formulation approach for topical delivery of hydrophobic drugs. International Research Journal Pharmacy 2013; 2:12-16.
[22] PtelChirag J, Satyanand t, Prabhaker S, Mrugendra B. Emulgel: A combination of Emulsion and gel. Journal Drug Discovery Therapeutics 2013; 6:57-61.

[23] Khullar R, Saini S, Sethi N, Rana AC. Emulgel: A surrogate approach for topically used hydrophobic drugs. Int $\mathrm{J}$ Pharm BiolSci 2011; 42:117-128.

[24] Mohamed MI. Topical emulsion gel composition comprising diclofenac sodium. Am Assn Pharmsci 2004; 3:514-545. 